\title{
Avaliação da Degradação de macrófitas Aquáticas Descartadas em Ambiente Protegido ${ }^{1}$
}

\author{
Assessment of the Degradation of Aquatic Macrophytes Discarded into a Protected Environment
}

\begin{abstract}
CEZAR, V.R.S. ${ }^{2}$, VILLAS BOAS, R.L. ${ }^{3}$, CORREA, M.R. ${ }^{4}$, NEGRISOLI, E. ${ }^{4}$ e VELINI, E.D. ${ }^{5}$
RESUMO - Com o intuito de buscar informações sobre a degradação de macrófitas aquáticas descartadas em pilhas, após ações do controle mecânico, foi conduzido um experimento no Departamento de Recursos Naturais - Ciências Ambientais, UNESP, campus de BotucatuSP. Para atender o objetivo proposto, foram montadas pilhas com volume de $2,25 \mathrm{~m}^{3}$, compostas, principalmente, por três espécies de macrófitas, retiradas do reservatório da UHE Americana/SP. Foram coletadas amostras na montagem das pilhas, aos 15, 30,60 e 90 dias, para o acompanhamento da temperatura da pilha e do $\mathrm{pH}$ do material orgânico durante o processo, além de uma análise química do composto ao final dos 90 dias. Os tratamentos foram: T1 - somente plantas aquáticas e revolvimento da pilha a cada sete dias; T2 - somente plantas aquáticas e revolvimento a cada quatro dias; T3 - plantas aquáticas + permagel, com revolvimento a cada sete dias; e T4 - plantas aquáticas + permagel e revolvimento a cada quatro dias. Utilizou-se o delineamento estatístico inteiramente casualizado, sendo a análise estatística realizada para coleta aos 90 dias, empregando o programa SISVAR. Concluiu-se que os resultados de macro e micronutrientes, temperatura, umidade, $\mathrm{pH}$, relação $\mathrm{C} / \mathrm{N}$ e redução do volume das pilhas foram semelhantes aos observados quando se procedeu ao descarte em pilhas com volume de 4,5 $\mathrm{m}^{3}$ sobre o solo.
\end{abstract}

Palavras-chave: macrófitas, temperatura, volume e área de descarte.

ABSTRACT - An experiment was carried out at the Department of Natural Resources - Environmental Science, UNESP, Botucatu-SP to evaluate the degradation of aquatic macrophytes discarded in stacks, after mechanical control measures. Stacks of $2.25 \mathrm{~m}^{3}$ volume were set up, composed of three species of macrophytes collected from the Americana UHE reservoir in Sao Paulo. Stack samples were collected at 15, 30, 60 and 90 days, for temperature monitoring and organic material pH assessment during the process, besides compound chemical analysis at day 90. The treatments were: T1-only aquatic plants with stack revolving every seven days; T2- only aquatic plants revolving every four days; T3- aquatic plants + permagel and revolving every seven days and T4-aquatic plants + permagel and revolving every four days. The experiment was arranged in a randomized design, with statistical analysis for collection at day 90, using the SISVAR program. Results from the study on macro and micronutrients, temperature, moisture, $\mathrm{pH}, \mathrm{C} / \mathrm{N}$ relation and stack volume reduction were similar to those observed with discard was in stacks of $4.5 \mathrm{~m}^{3}$ volume.

Key words: macrophytes, temperature, discard volume and area.

1 Recebido para publicação em 5.1.2005 e na forma revisada em 6.4.2005.

2 Eng.-Agr., Programa de Pós-Graduação em Energia na Agricultura, FCA/UNESP, Caixa Postal 237, 18603-970 Botucatu-SP, $<$ vrscezar@fca.unesp.br>; ${ }^{3}$ Prof. Dr., Departamento de Ciência do Solo, FCA/UNESP, Botucatu-SP; ${ }^{4}$ Eng.-Agr., M.S., Programa de Pós-Graduação em Agricultura, Departamento de Produção Vegetal/Agricultura, FCA/UNESP, Botucatu-SP; ${ }^{5}$ Prof. Assistente Dr., Departamento de Produção Vegetal/Agricultura, FCA/UNESP, Botucatu-SP. 


\section{INTRODUÇÃO}

No Brasil, lagos e rios são importantes por fornecerem água e dar suporte a sistemas de produção agrícola e industrial, consumo humano, recreação, navegação, irrigação, pesca, além da geração de energia elétrica. O carregamento de parte dos fertilizantes utilizados em culturas agrícolas e a grande carga de esgotos residenciais e industriais têm levado cursos e reservatórios a uma condição de desequilíbrio, caracterizada pela grande disponibilidade de nutrientes, acelerando o crescimento de vegetação aquática indesejável, incluindose algas e plantas superiores (Velini, 2000).

A ocorrência de plantas aquáticas em reservatórios de hidrelétricas é um problema de importância crescente. Algumas hidrelétricas já têm sua eficiência comprometida pela elevada infestação de plantas aquáticas, como o caso do reservatório da UHE Americana/SP, que apresenta aproximadamente $20 \%$ de sua superficie coberta por essas plantas, causando grandes problemas ao seu uso por partae da CPFL e pela comunidade local.

São poucas as opções para controle de plantas aquáticas no Brasil. A única alternativa que vem sendo utilizada é o controle mecânico. Como qualquer outro método de controle de plantas aquáticas, este apresenta vantagens e limitações. Segundo Velini (2000), as operações relacionadas ao controle mecânico podem ser divididas em quatro etapas: retirada das plantas dos rios, canais ou lagos; transporte das plantas ainda no corpo hídrico; transferência desse material para o ambiente terrestre; e transporte e descarte do material coletado.

O controle mecânico apresenta como vantagens a não-contaminação da água com compostos químicos de ação herbicida ou toxinas e o fato de poder ser utilizado de modo pontual, limitando-se o controle aos locais de ocorrência das plantas. As plantas são, geralmente, retiradas do meio aquático, reduzindo os problemas resultantes de sua decomposição na água, como consumo de oxigênio, odor e aparência desagradável da água. Como desvantagens, destacam-se a inespecificidade, a possibilidade de segmentação das plantas com propagação vegetativa, o elevado custo e a necessidade de áreas de descarte quando as plantas são removidas do corpo hídrico. O elevado custo, em grande parte, depende da necessidade de criação e manutenção de áreas de descarte.

O procedimento correto para promover a decomposição de plantas aquáticas, sem ultrapassar a capacidade de suporte do ambiente das áreas de descarte, consiste em aplicar periodicamente a biomassa vegetal, permitindo que esta tenha tempo para desidratar e decompor. A aceleração da decomposição da biomassa é fundamental para que as áreas de descarte sejam utilizadas com máxima eficiência. A decomposição pode ser intensificada pela fragmentação do material vegetal, melhorando o contato com o solo e a penetração de microrganismos, além da seleção, multiplicação e aplicação de microrganismos degradadores.

Deve ser mencionado que informações sobre sistemas de controle mecânico e descarte de plantas aquáticas praticamente inexistem no Brasil, destacando-se os trabalhos de Velini (1998, 2000) e Corrêa (2002). Desse modo, este estudo foi constituído com a finalidade de levantar informações que permitam compreender os processos de decomposição de macrófitas em áreas de descarte após ações de controle mecânico.

\section{MATERIAL E MÉTODOS}

O estudo foi conduzido no Departamento de Recursos Naturais/Ciências Ambientais, campus da UNESP de Botucatu, São Paulo, por um período de 90 dias. Foram montadas pilhas de compostagem, com volume de $2,25 \mathrm{~m}^{3}$, compostas principalmente por três espécies infestantes do reservatório de Americana/SP: Eichhornia crassipes, Pistia Stratiotes e Brachiaria subquadripara. As pilhas foram acomodadas em ambiente protegido.

Os tratamentos empregados foram: $\mathrm{T} 1$ somente plantas aquáticas e revolvimento da pilha a cada sete dias; T2 - somente plantas aquáticas e revolvimento a cada quatro dias; T3 - plantas aquáticas + Permagel, com revolvimento a cada sete dias; e T4 - plantas aquáticas + Permagel e revolvimento a cada quatro dias.

Nos tratamentos T3 e T4 foi utilizado um produto denominado "Permagel", que é uma 
argila capaz de absorver $250 \%$ do seu peso em água; suas características podem ser vistas na Tabela 1. O objetivo da utilização deste produto foi o de remover o excesso de água da biomassa, deixando-a em condições ideais de umidade para a decomposição, que, de acordo com Kiehl (1998), seria em torno de 50\%.

O delineamento experimental foi o inteiramente casualizado, com quatro tratamentos e três repetições.

O revolvimento das pilhas não tem condições de ser utilizado em campo, mas foi fundamental para que houvesse possibilidade de coleta de amostras representativas do material em decomposição. Foram realizadas coletas de amostras nos diferentes tratamentos, na montagem das pilhas (Figura 1), aos 15 (Figura 2), aos 30 (Figura 3), aos 60 (Figura 4) e aos 90 dias (Figura 5) após a confecção destas. O tamanho das partículas do material submetido à decomposição aeróbia também foi medido, estando os resultados apresentados na Tabela 2.

Nessas amostras, foram analisados os teores de macro e micronutrientes, carbono orgânico, pH e umidade, segundo metodologia descrita no LANARV (1988). Somente na última coleta foi feita análise estatística, utilizando o programa SISVAR, por ela representar o término do ensaio. Os resultados podem ser vistos nas Tabelas 4, 5 e 6 .

Foi realizado, durante o ensaio, um monitoramento diário da temperatura interna das pilhas de biomassa descartada; os resultados podem ser observados na Figura 6.

\section{RESULTADOS E DISCUSSÃO}

Como pode ser observado na Figura 6, houve aumento de temperatura em todos os tratamentos, sendo os valores superiores aos da temperatura do ambiente. Os valores ficaram abaixo daquele citado por Kiehl (1988) como ideal para o processo de decomposição. Esse autor afirma que a temperatura ideal, principalmente na etapa que vai de 0 a 30 dias, deve ser de até $65^{\circ} \mathrm{C}$. Essa temperatura é importante para profilaxia do material, destacando-se a inviabilização dos propágulos das próprias plantas coletadas e descartadas.

Tabela 1 - Características químicas do Permagel, utilizado para controle da umidade nos tratamentos T3 e T4. Botucatu-SP, 2004

\begin{tabular}{|c|c|c|c|c|c|c|c|c|c|c|}
\hline \multirow{2}{*}{ Produto } & $\mathrm{Cu}$ & $\mathrm{Zn}$ & $\mathrm{Mn}$ & $\mathrm{Fe}$ & $\mathrm{Ca}$ & $\mathrm{S}$ & $\mathrm{Mg}$ & $\mathrm{K}$ & $\mathrm{N}$ & $\mathrm{P}$ \\
\hline & \multicolumn{4}{|c|}{$\left(\mathrm{mg} \mathrm{kg}^{-1}\right)$} & \multicolumn{6}{|c|}{$\left(\mathrm{g} \mathrm{kg}^{-1}\right)$} \\
\hline Permagel & 46 & 88 & 54 & 3060 & 8,6 & 1,0 & 19,9 & 0,6 & 0,8 & 0,3 \\
\hline
\end{tabular}
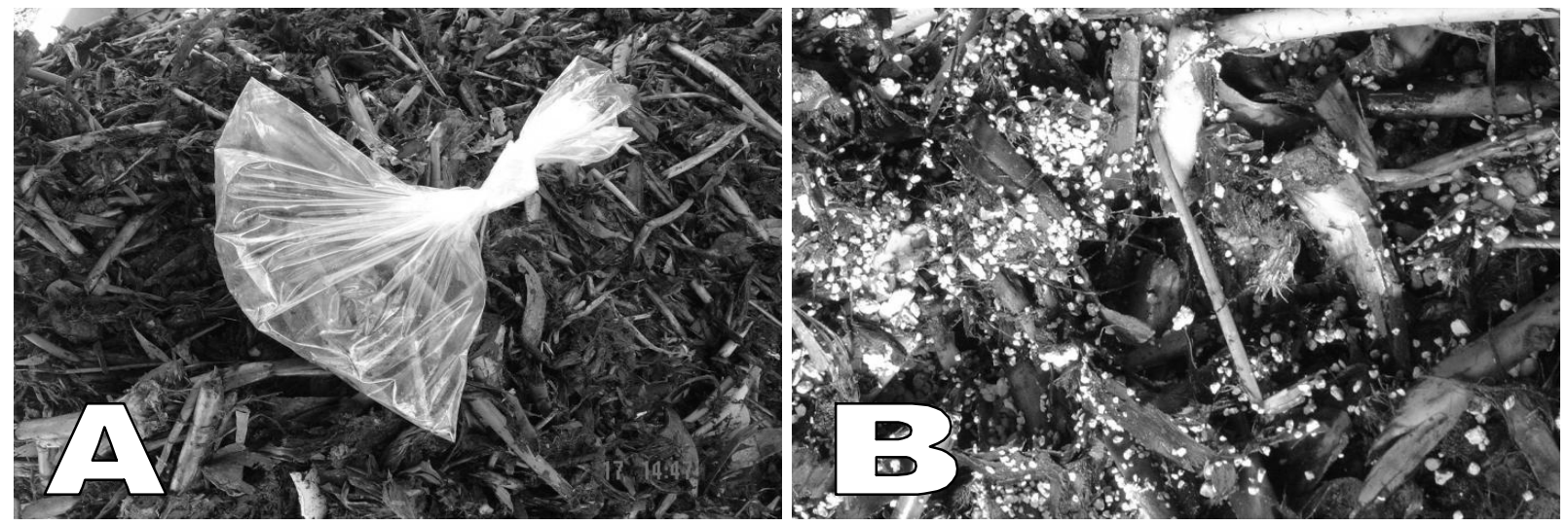

Figura 1 - Aspecto das plantas amostradas durante a primeira coleta nos tratamentos sem (A) e com Permagel (B). Botucatu-SP, 2004. 

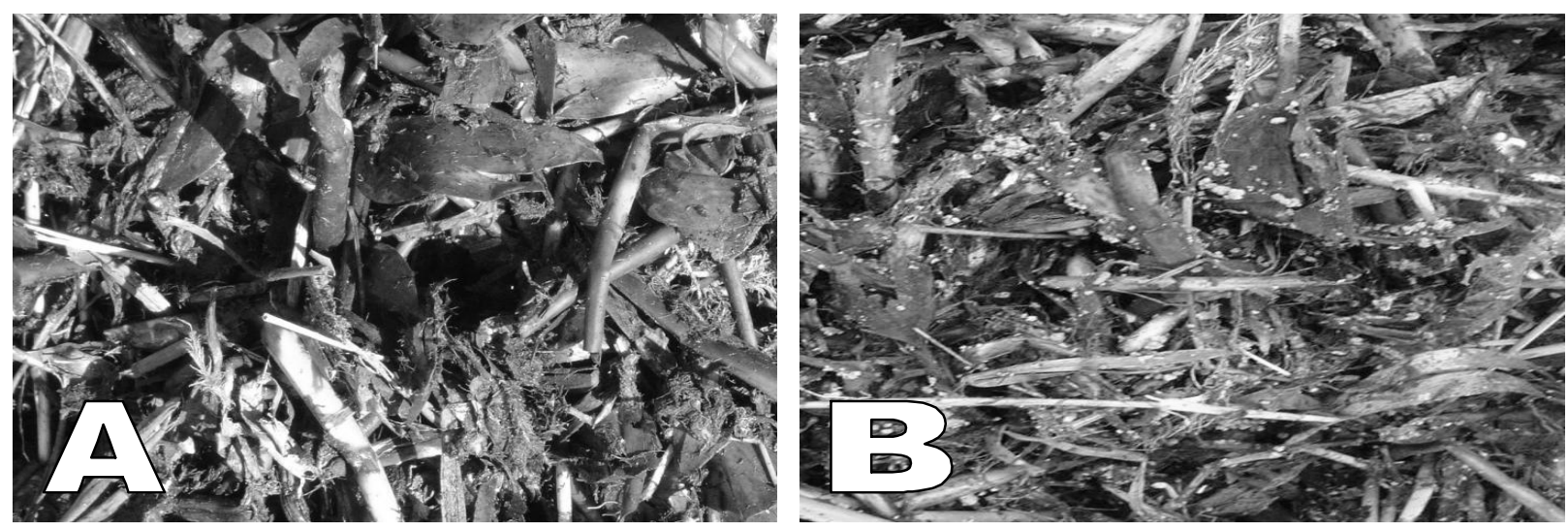

Figura 2 - Aspecto das plantas durante a coleta realizada aos 15 dias nos tratamentos sem (A) e com Permagel (B). Botucatu-SP, 2004.
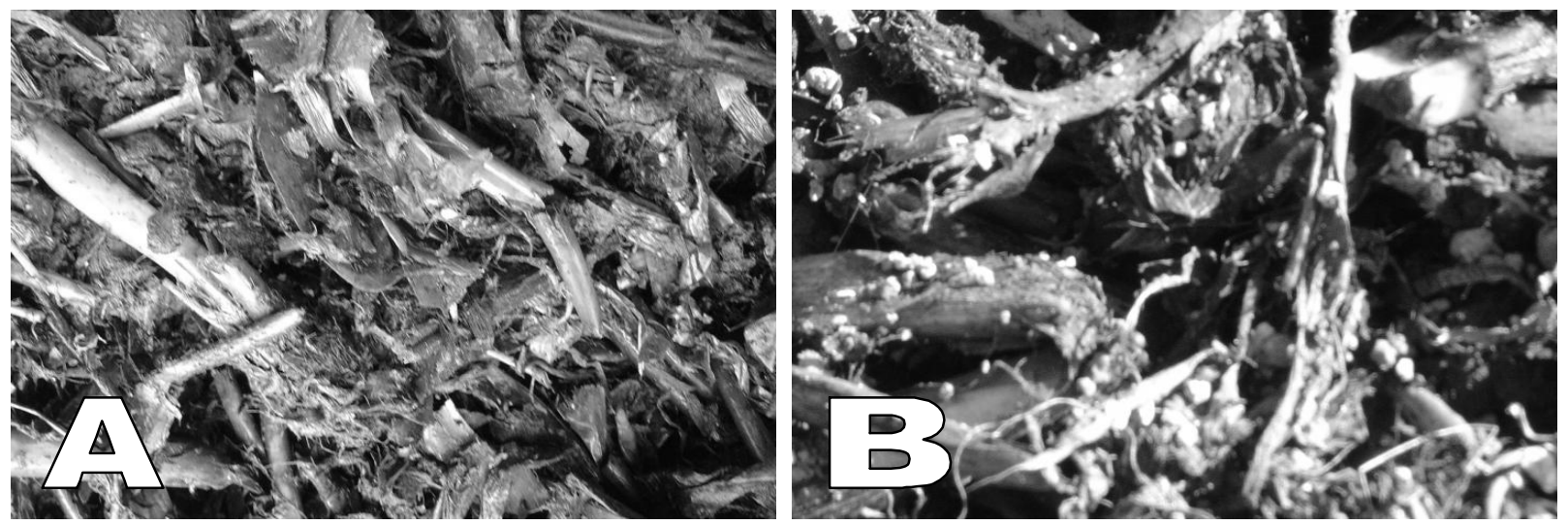

Figura 3 - Aspecto das plantas durante a coleta realizada aos 30 dias nos tratamentos sem (A) e com Permagel (B). Botucatu-SP, 2004.
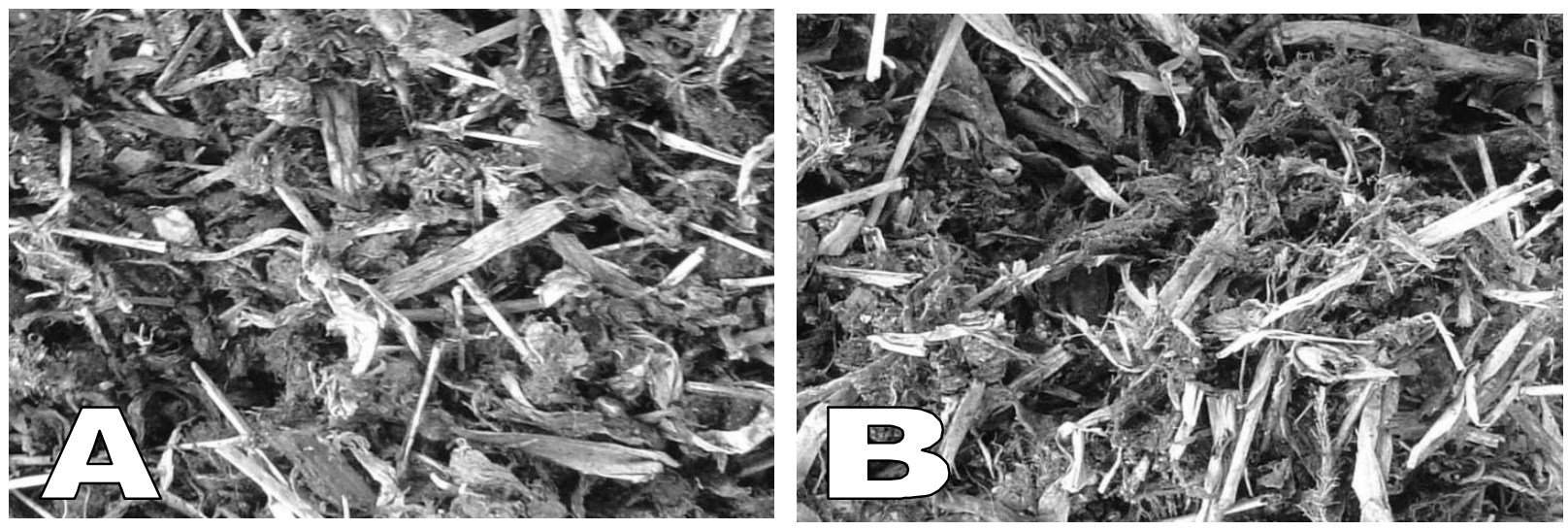

Figura 4 - Aspecto das plantas durante a coleta realizada aos 60 dias nos tratamentos sem (A) e com Permagel (B). Botucatu-SP, 2004. 

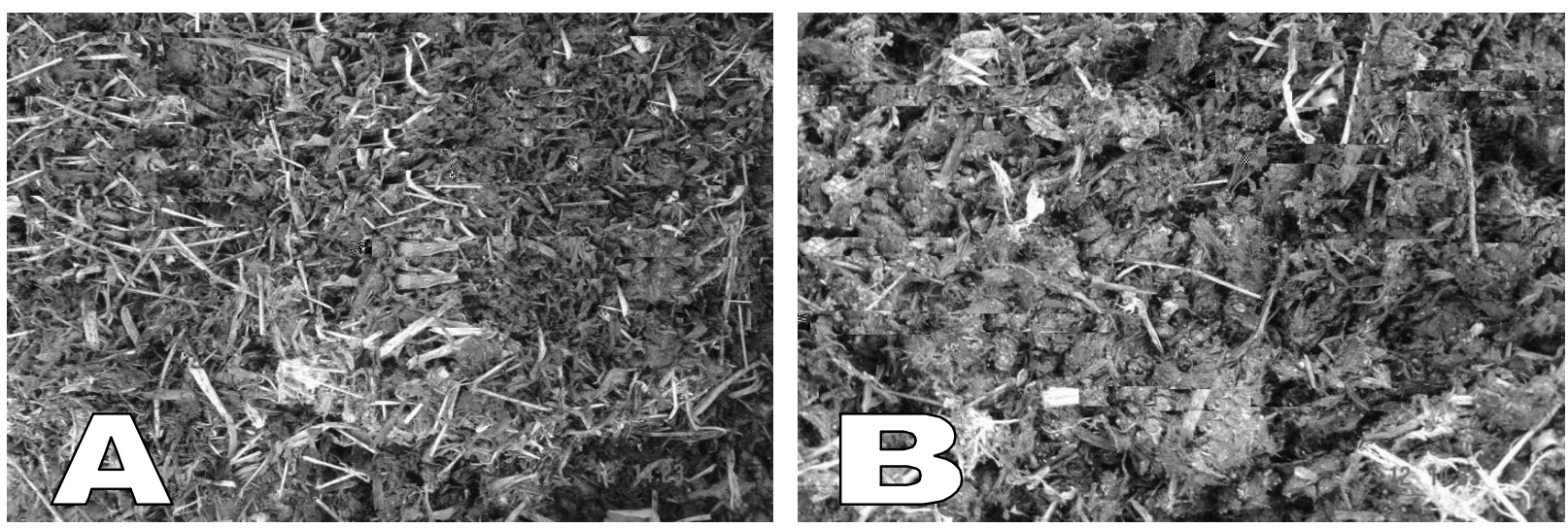

Figura 5 - Aspecto das plantas durante a coleta realizada aos 90 dias nos tratamentos sem (A) e com Permagel (B). Botucatu-SP, 2004.

Tabela 2 - Dimensões dos fragmentos (cm) de plantas aquáticas utilizadas na confecção de montes no ensaio de degradação. Botucatu-SP, 2004

\begin{tabular}{|c|c|c|c|c|c|}
\hline \multicolumn{4}{|c|}{ Eichhornia crassipes } & \multicolumn{2}{c|}{ B. subquadripara } \\
\hline \multicolumn{2}{|c|}{ Parte aérea } & \multicolumn{2}{c|}{ Sistema radicular } & \multicolumn{2}{c|}{ Parte aérea + S. radicular } \\
\hline Comprimento & Largura & Comprimento & Largura & Comprimento & Largura \\
\hline 11,79 & 1,95 & 10,62 & 1,81 & 16,90 & 0,35 \\
\hline
\end{tabular}

Tabela 3 - Teores de macronutrientes e carbono orgânico total, expressos em $\mathrm{g} \mathrm{kg}^{-1}$, e relação C/N, determinados na primeira coleta para os respectivos tratamentos. Botucatu-SP, 2004

\begin{tabular}{|c|c|c|c|c|c|c|c|c|}
\hline Tratamento & $\mathrm{N}$ & $\mathrm{P}$ & $\mathrm{K}$ & $\mathrm{Ca}$ & $\mathrm{Mg}$ & $\mathrm{S}$ & $\mathrm{C}$ & $\mathrm{C} / \mathrm{N}$ \\
\hline $\mathrm{T} 1$ & 15,3 & 2,8 & 17,9 & 40,4 & 9,7 & 5,6 & 289,6 & 19,13 \\
$\mathrm{~T} 2$ & 15,7 & 2,8 & 19,5 & 42,4 & 10,1 & 5,8 & 306,0 & 19,76 \\
\hline $\mathrm{T} 3$ & 10,4 & 2,1 & 11,7 & 28,3 & 13,3 & 4,2 & 217,1 & 21,21 \\
\hline T4 & 9,7 & 1,7 & 9,9 & 26,4 & 14,8 & 3,6 & 217,1 & 22,46 \\
\hline
\end{tabular}

Tabela 4 - Teores de macronutrientes e carbono orgânico total, expressos em $\mathrm{g} \mathrm{kg}^{-1}$, e relação $\mathrm{C} / \mathrm{N}$, determinados na coleta final para os respectivos tratamentos. Botucatu-SP, 2004

\begin{tabular}{|c|c|c|c|c|c|c|c|c|}
\hline Tratamento & $\mathrm{N}$ & $\mathrm{P}$ & $\mathrm{K}$ & $\mathrm{Ca}$ & $\mathrm{Mg}$ & $\mathrm{S}$ & $\mathrm{C}$ & $\mathrm{C} / \mathrm{N}$ \\
\hline $\mathrm{T} 1$ & $18,75 \mathrm{a}$ & $3,50 \mathrm{a}$ & $22,25 \mathrm{a}$ & $51,25 \mathrm{a}$ & $9,75 \mathrm{a}$ & $7,75 \mathrm{a}$ & $177,2 \mathrm{ab}$ & $9,75 \mathrm{a}$ \\
$\mathrm{T} 2$ & $20,25 \mathrm{a}$ & $3,75 \mathrm{a}$ & $21,50 \mathrm{a}$ & $52,50 \mathrm{a}$ & $10,25 \mathrm{a}$ & $8,00 \mathrm{a}$ & $230,7 \mathrm{~b}$ & $11,50 \mathrm{a}$ \\
$\mathrm{T} 3$ & $12,25 \mathrm{a}$ & $2,00 \mathrm{~b}$ & $13,25 \mathrm{~b}$ & $33,75 \mathrm{~b}$ & $13,75 \mathrm{~b}$ & $4,75 \mathrm{a}$ & $131,0 \mathrm{a}$ & $10,25 \mathrm{a}$ \\
$\mathrm{T} 4$ & $13,00 \mathrm{~b}$ & $1,75 \mathrm{~b}$ & $14,25 \mathrm{~b}$ & $35,75 \mathrm{~b}$ & $14,25 \mathrm{~b}$ & $4,75 \mathrm{a}$ & $150,0 \mathrm{a}$ & $11,75 \mathrm{a}$ \\
\hline $\mathrm{CV} \%$ & 8,85 & 16,6 & 17,05 & 7,64 & 12,5 & 6,86 & 16,11 & 13,94 \\
\hline
\end{tabular}

Comparação de médias pelo teste de Tukey a $5 \%$ de probabilidade.

Letras minúsculas na mesma coluna comparam médias entre os tratamentos.

Com base nos valores de temperatura, pode-se observar que eles não atingiram aqueles considerados ideais. Provavelmente isso tenha ocorrido em razão do tamanho das partículas dos materiais submetidos ao processo de decomposição (Tabela 2). Desse modo, seria 
interessante que o material fosse ainda mais fragmentado ou que as pilhas tivessem maiores dimensões.

A fragmentação mais intensa do material implica o desenvolvimento de equipamentos mais eficazes do que os utilizados neste estudo. O aumento do tamanho das pilhas também é uma alternativa de dificil operacionalização, devido à dificuldade em constituir montes maiores a partir do material transportado com caminhões basculantes.

Os volumes das pilhas de biomassa durante a condução do experimento são apresentados na Figura 7. Observa-se redução de aproximadamente $80 \%$ no volume das pilhas em praticamente todos os tratamentos. Em complementação, a adição do Permagel não alterou a velocidade de decomposição, não justificando o seu uso.

O revolvimento periódico das pilhas, necessário para uniformização e amostragem do

Tabela 5 - Teores de micronutrientes $\left(\mathrm{mg} \mathrm{kg}^{-1}\right)$ encontrados na biomassa em decomposição durante a amostragem final, em função dos seus respectivos tratamentos. Botucatu-SP, 2004

\begin{tabular}{|c|c|c|c|c|}
\hline Tratamento & $\mathrm{Cu}$ & $\mathrm{Zn}$ & $\mathrm{Mn}$ & $\mathrm{Fe}$ \\
\hline $\mathrm{T} 1$ & $54,75 \mathrm{a}$ & $146,00 \mathrm{a}$ & $716,75 \mathrm{a}$ & $10.976,75 \mathrm{a}$ \\
$\mathrm{T} 1$ & $39,25 \mathrm{a}$ & $120,75 \mathrm{a}$ & $671,75 \mathrm{a}$ & $11.321,25 \mathrm{a}$ \\
$\mathrm{T} 2$ & $46,75 \mathrm{a}$ & $117,50 \mathrm{a}$ & $432,25 \mathrm{a}$ & $15.528,00 \mathrm{~b}$ \\
\hline $\mathrm{T} 4$ & $41,25 \mathrm{a}$ & $141,00 \mathrm{a}$ & $419,25 \mathrm{a}$ & $15.867,00 \mathrm{~b}$ \\
\hline $\mathrm{CV} \%$ & 21,75 & 24,62 & 7,32 & 11,31 \\
\hline
\end{tabular}

Comparação de médias pelo teste de Tukey a 5\% de probabilidade.

Letras minúsculas na mesma coluna comparam médias entre os tratamentos.

Tabela 6 - Resultados de pH e umidade a 65 e $105{ }^{\circ} \mathrm{C}$, expressos em \%, determinados na última coleta, em função dos seus respectivos tratamentos. Botucatu-SP, 2004

\begin{tabular}{|c|c|c|c|}
\hline Tratamento & $\mathrm{pH}$ & ${\text { Umidade } 65^{\circ}}^{\circ}$ & Umidade $105^{\circ}$ \\
\hline T1 & $7,75 \mathrm{a}$ & $78,75^{\mathrm{a}}$ & $79,00 \mathrm{a}$ \\
\hline T2 & $8,00 \mathrm{a}$ & $77,75^{\mathrm{a}}$ & $78,25 \mathrm{a}$ \\
\hline T3 & $8,00 \mathrm{a}$ & $75,00 \mathrm{~b}$ & $75,00 \mathrm{~b}$ \\
\hline T4 & $8,00 \mathrm{a}$ & $76,00 \mathrm{~b}$ & $76,00 \mathrm{~b}$ \\
\hline CV $\%$ & 3,15 & 2,04 & 7,32 \\
\hline
\end{tabular}

Comparação de médias pelo teste de Tukey a 5\% de probabilidade.

Letras minúsculas na mesma coluna comparam médias entre os tratamentos.

Planta Daninha, Viçosa-MG, v. 23, n. 2, p. 255-261, 2005 material, teve uma segunda função importante: a inviabilização do desenvolvimento dos propágulos de Brachiaria subquadripara. O resultado foi considerado satisfatório, pois as pilhas não foram colonizadas por esta espécie. O espaçamento de tempo entre os revolvimentos também não interferiu na velocidade do processo de decomposição, indicando que a falta de oxigênio ou o excesso de $\mathrm{CO}_{2}$ não foram fatores limitantes à decomposição. Esses gases apresentam grande facilidade de difusão, garantindo, por exemplo, a presença de atividade aeróbica mesmo a alguns metros de profundidade em solos.

De acordo com os dados da Tabela 4, observa-se que ocorreu diferença significativa entre os tratamentos T1 e T2, quando comparado com T3 e T4, no que se refere aos teores de macronutrientes presentes na biomassa em decomposição. Essa diferença pode ser relacionada com a heterogeneidade da biomassa utilizada, uma vez que se encontram diferentes

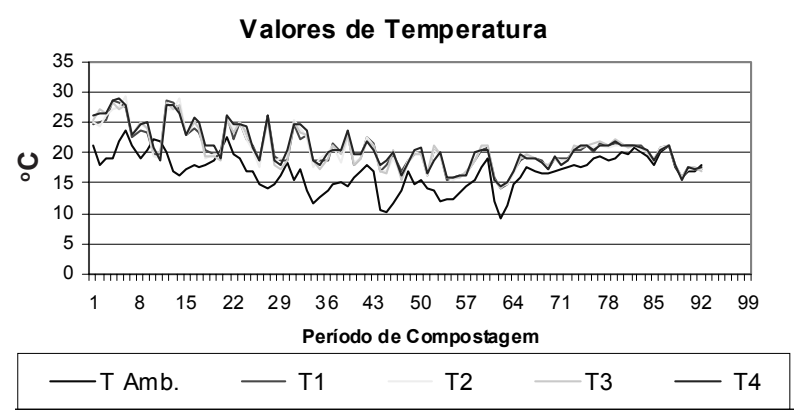

Figura 6 - Valores de temperatura no interior das pilhas com plantas aquáticas, em função de seus tratamentos. Botucatu-SP, 2004.

\section{Redução das pilhas de compostagem}

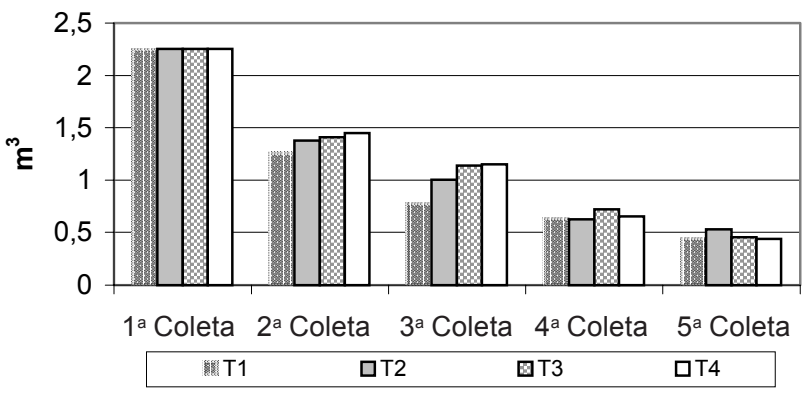

Figura 7 - Volume das pilhas de biomassa em função da época de amostragem. Botucatu-SP, 2004. 
espécies de plantas aquáticas nos mais diversos estágios de desenvolvimento. Portanto, mesmo que seja utilizado o método de amostragem citado por Kiehl (1998), pode ocorrer variação nos resultados em decorrência da diversificação de espécies contidas nos reservatórios.

Para a relação carbono/nitrogênio (Tabela 4), não foi observada diferença significativa entre os tratamentos. Verifica-se também que o processo ocorreu de forma adequada, levando à queda da relação carbono/nitrogênio, quando comparada ao material orgânico inicial submetido ao processo de degradação (Tabela 2).

$\mathrm{Na}$ Tabela 5 são apresentados os resultados de micronutrientes determinados na coleta final, aos 90 dias após o início do processo de decomposição. Observa-se que não houve diferença estatística entre os tratamentos. Somente ocorreu diferença significativa para o conteúdo de ferro, em que T1 e T2 são estatisticamente inferiores aos tratamentos com Permagel. Esse aumento no conteúdo de ferro pode estar relacionado com a adição do produto, o qual contém este elemento em sua composição.

Na Tabela 6 são apresentados os valores de $\mathrm{pH}$ e umidade a 65 e $105^{\circ} \mathrm{C}$ da última coleta. Os índices de $\mathrm{pH}$ apresentados não indicaram diferenças significativas entre os tratamentos, nem mesmo quanto o Permagel foi adicionado. No entanto, para os percentuais de umidade avaliados a 65 e $105^{\circ} \mathrm{C}$, observaram-se diferenças estatísticas quando comparados os tratamentos sem e com o produto. Nesse caso, a utilização do Permagel favoreceu a perda de água da massa vegetal submetida à decomposição. Essa perda de água foi considerada pequena e não chegou ao valor ideal de umidade (em torno de 50\%) considerado como ótimo para o processo de decomposição. De qualquer modo, levando-se em conta o custo adicional, não se justifica, o uso do Permagel, tendo em vista as pequenas vantagens encontradas.

Conclui-se que a intensidade de decomposição encontrada neste estudo, levando em consideração todos os parâmetros avaliados, provavelmente esteja próxima ao limite do que pode ser observado em campo.

\section{AGRADECIMENTOS}

À CPFL e ANEEL, pelo suporte técnico e financeiro durante a execução deste estudo.

\section{LITERATURA CITADA}

CORRÊA, M. R. Composição química, bromatológica e decomposição de plantas de Egeria densa, Egeria najas e Ceratophyllum demersum coletadas no reservatório da Usina Hidrelétrica de Jupiá. 2002. 101 f. Dissertação (Mestrado em Agronomia) - Universidade Estadual Paulista, Botucatu, 2002.

KIEHL, E. J. Manual de compostagem "Maturação e qualidade do composto". Piracicaba: 1998. $171 \mathrm{p}$.

LABORATÓRIO NACIONAL DE REFERÊNCIA VEGETAL - LANARV. Análise de corretivos, fertilizantes e inoculantes - métodos oficiais. Brasília: Ministério de Agricultura, Secretaria Nacional de Defesa Agropecuária, 1988. 104 p.

VELINI, E. D. Controle mecânico de plantas daninhas aquáticas no Brasil. In: WORKSHOP CONTROLE DE PLANTAS AQUÁTICAS. Brasília: IBAMA, 1998. p. 32-35.

VELINI, E. D. Controle de plantas daninhas aquáticas. In: CONGRESSO BRASILEIRO DA CIÊNCIA DAS PLANTAS DANINHAS, 22., 2000, Foz do Iguaçu. Palestras... Foz do Iguaçu: SBCPD, 2000. p. 137-147. 